\title{
Ability and Behavior of Students to Represent and Transform a Physical System
}

\author{
Artista Prihastuti \\ Postgraduate of science education \\ Universitas Tadulako \\ Palu, Indonesia
}

Jusman Mansyur

Dept. of Mathematic and Science Education

Universitas Tadulako

Palu, Indonesia

jusman_mansyur@untad.ac.id

\author{
Muh. Rizal \\ Dept. of Mathematic and Science Education \\ Universitas Tadulako \\ Palu, Indonesia
}

\begin{abstract}
This research aims to describe abilities and behavior of students in representing and transforming a physical system. Respondents of the research were two selected students of the first year from two categories (in the group) based on a selection test. Research instruments consisted of a respondent selection test, a test of ability and behavior in representing and transforming physical system and an interview protocol. Research data were analyzed by qualitative analysis. Based on the data analysis, it can be stated that the ability of the respondents in transforming the physical system were in a low category. The respondents were more able to transform a verbal representation into a mathematical representation. There is a dependence of the ability to transform a representation towards an initial representation to a target of representation and the context underlying the physical system.
\end{abstract}

Keywords-represent; transform; ability; behavior; physics problem solving;

\section{INTRODUCTION}

The ability of representation is an ability to interpret and apply the various representations and explain physics concepts and physics problems [1]. Ref.[2] has developed an assessment rubric on the ability to represents a physics problem. There are four capabilities representing an information, i.e: ability to extract information, ability to form new representation(s) from previous representation(s), evaluate a consistency of different representations and ability to use representations in problemsolving.

Representation involves a translation. It is begun with writing a verbal description of the problem, forming customized drawings or diagrams, and it is ended with a mathematical formula that can be used to determine the answer using numbers [3]. Verbal representation represents a concept or physical processes such as words or sentence. Image representation is a representation that presents a concept or in form of actual physical process, that is similar to the original. Images can visualize abstract concepts so that it can be easily understood by problem solver. Physical representation is a representation of a concept or physical processes through physical forms such as free-body diagram or chart of motion of objects. The mathematical representation of a physics concept or process is presented in the form of a mathematical equation.

In a problem-solving process, problem solver should be able to integrate an external representation to other representations. Ref.[4] found a failure of students in physics problem solving was caused by an inability of students in integrating a diagram and a mathematical representation. The use of representations is very important for students because it is needed in a troubleshooting process [1].

This study examined the capability and behavior of students to represent and transform the physical system. Aspects of representation and their transformation can be analyzed in physics problem-solving.

\section{METHOD}

This research is a qualitative research using a descriptive method. Subjects of the research were 22 first-year students. Respondents of the research were 2 students that consisted of two categories (in the group) based on mastery of concepts. The categories were high and low in ability.

Instruments of the research were a test for thinking-aloud and an interview protocol. Data of ability to represent and transform physical systems were obtained through one-on-one thinking-aloud, and it was followed by in-depth interviews. The activities were recorded using a video camera. Recordings data from the thinking aloud were transferred to transcripts. Assessment rubric of ability to represent and transform the physical system is presented in Table I.

We used triangulation method to ensure the credibility of data by comparing thinking-aloud and interview transcript and written answer of the respondents. 
TABLE I. RUBRIC OF THE ABILITY AND BEHAVIOR OF STUDENTS TO REPRESENT AND TRANSFORM A PHYSICAL SYSTEM

\begin{tabular}{|c|c|c|}
\hline No. & Assessment & Score \\
\hline \multirow{4}{*}{1} & No answer & 0 \\
\hline & Making a chart base on information of question & 1 \\
\hline & $\begin{array}{l}\text { Making a chart base on the information of question } \\
\text { Formulating a mathematical equation base on the graph } \\
\text { according to information of question }\end{array}$ & 2 \\
\hline & $\begin{array}{l}\text { Making a chart base on the information of question } \\
\text { Formulating a mathematical equation base on the graph } \\
\text { according to information of question } \\
\text { Correct answer }\end{array}$ & 3 \\
\hline \multirow{4}{*}{2} & No answer & 0 \\
\hline & $\begin{array}{l}\text { Formulating a mathematical equation base on data in the } \\
\text { graph }\end{array}$ & 1 \\
\hline & $\begin{array}{l}\text { Formulating a mathematical equation base on data in the } \\
\text { graph } \\
\text { Writing information base on the mathematical equation } \\
\text { according to data in the graph }\end{array}$ & 2 \\
\hline & $\begin{array}{l}\text { Formulating a mathematical equation base on data in the } \\
\text { graph } \\
\text { Writing information base on the mathematical equation } \\
\text { according to data in the graph } \\
\text { Correct answer }\end{array}$ & 3 \\
\hline \multirow{4}{*}{3} & No answer & 0 \\
\hline & $\begin{array}{l}\text { Making a chart base on mathematical equations } \\
\text { according to the question }\end{array}$ & 1 \\
\hline & $\begin{array}{l}\text { Making a chart base on mathematical equations } \\
\text { according to the question } \\
\text { Writing information base on the graph according to } \\
\text { mathematical equation in the question }\end{array}$ & 2 \\
\hline & $\begin{array}{l}\text { Making a chart base on mathematical equations } \\
\text { according to the question } \\
\text { Writing information base on the graph according to } \\
\text { mathematical equation in the question } \\
\text { Correct answer }\end{array}$ & 3 \\
\hline
\end{tabular}

\section{RESULT AND DISCUSSION}

In the following sections, we present a description of the process of representing and transforming the physical system. To support the description, we present written answer sheets, transcripts thinking-aloud, and transcripts of the interview. This section also presents scores of representing capabilities and transform the physical system by referring the rubric.

There were three selected problems according to the design and function to enable the capabilities and behavior of students to represent and transform the physical system. Further discussions will be started to the items about representing every category of representation and transformation: A) Representation and Transformation Verbal-GraphMathematical Equations; B) Representation and Transformation Graph-Verbal Mathematical Equations; and C) Representation and Transformation Mathematical EquationGraph-Verbal.

\section{A. Representation and Transformation: Verbal-Graphics- Mathematically}

To determine the ability of respondents in transforming external representation, used about No. 1 (Fig. 1). The matter requires respondents to describe the phenomenon through the graph. Charts were then transformed into the form of a mathematical representation.

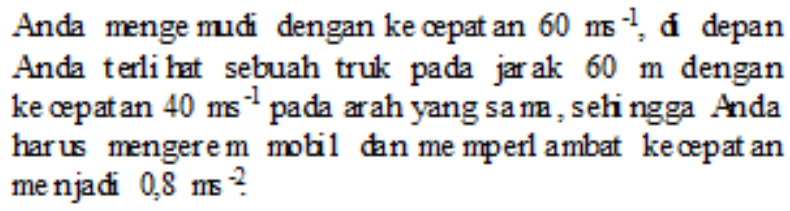

Buat gafik yang menggambarkan soa tersebut. Tert ukan apakah takx akan akan terjad ? I ka ya, kapan?

Fig 1. Description of Problem 1

Graph made by RKR to Problem 1 is presented in Fig. 2. The graph illustrates that $\mathrm{He}$ was unable to make verbal representations to the diagrammatic representation. Graphic representations do not show the trajectories of both cars. As a result, $\mathrm{He}$ was confused in determining whether the collision occurred on both cars.

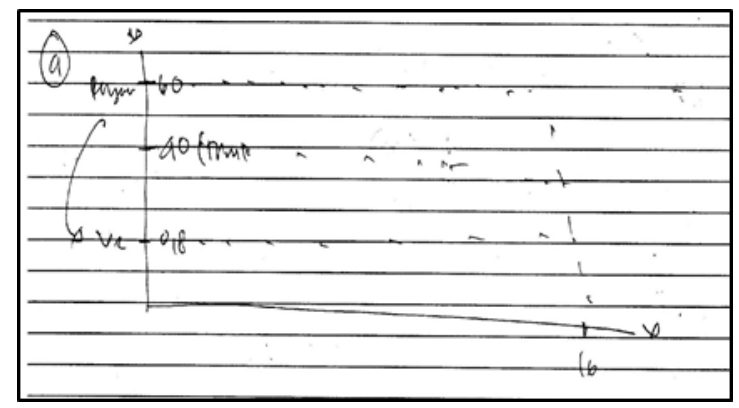

Fig 2. Graph by RKR for Problem 1

The above statement is reinforced in the session the following interview:

Interviewer: Can you explain the purpose of the graph

RKR: of $X$ to $Y$ you make?

$\{-\}<$ while drawing graphs> Naah here right from the driver's speed of $60 \mathrm{~ms}^{-1,}\{-\}$ keep on trucking $40 \mathrm{~ms}^{-1}$ so change the speed here is [...] actually I enter an acceleration value of $0.8 \mathrm{~ms}^{-2}$ on the charts.

Fig. 2 shows that the RKR has been trying to represent the event in the form of graphs. However, the resulting graph is not adequate so that he troubles to do next transformation.

When determining whether a collision will occur, RKR comparing the initial speed of cars and trucks. This process is a form of transformation into the form of a graphic representation of mathematical equations. Although the respondent has transformed from a graphical representation to a mathematical representation. He did not use a mathematical equation GLB and uniformly accelerated motion as demanded in the matter. This is consistent with the findings of [5] that learners have the opportunity to solve problems correctly when they enter a representation of charts/graphs as part of problemsolving. 
$\{-\}$ comparison of the speed at first it was 60 to 40 so that 3 compared with 2 well after the driver drove ... to reduce the pace of progress to 59.5 compared with 40 so ... only 2.95 compared with 2 speed only between the driver and the truck was just different 0,95 so I think it could be a collision due to the speed of the driver and the truck is the same

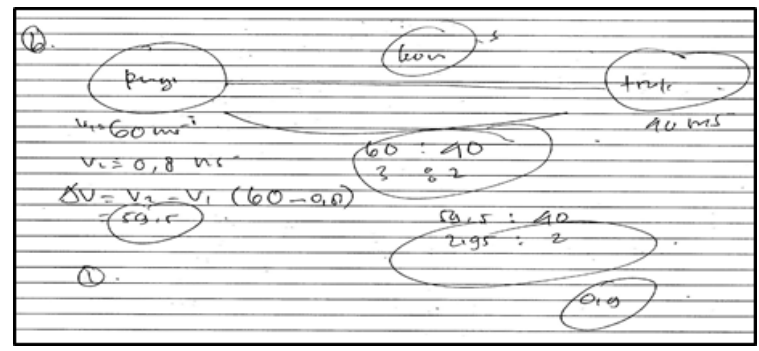

Fig 3. RKR's answer sheet for graph-mathematical transformation

\section{B. Representation and Transformation: Graphics-} Mathematical-Verbal

Problem number two (Fig. 4) requires the respondent to make representations in graphical form to a mathematical representation. Then respondents transform into a form of verbal representation.

Tentukan persamaan gerak sebuah benda yang diwakili oleh grafik berikut.

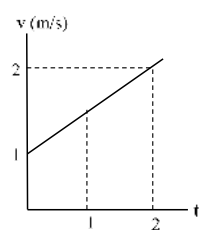

Apa makna persamaan kecepatan dari grafik tersebut (lakukan intepretasi)

Fig 4. Description of Problem 2

Based on Fig. 5. Representation RKT tends to refer directly to the equation of uniformly accelerated motion. He does not use the information presented on the graph. RKT is able to perform mathematical representation to the graphical representation but using concepts that are not appropriate. While in transforming verbal, RKT interpreted the equations are not physically and not based on the information on the chart. The behavior was also found in [4].

The description above is in line with Ref. [1] which stated that the work of the respondents on issues in physics depends on the representation issue, but dependence complex. The combination of representation, topics, and can result in selection of respondents' experience strategies used in working on issues of representation

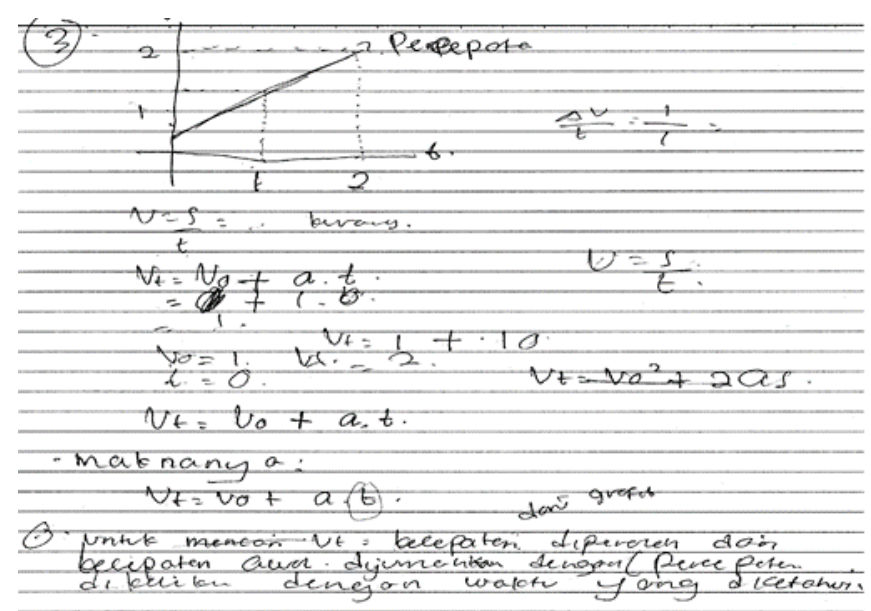

Fig 5. Answer Sheet RKT represent and transform

Here are excerpts of transcripts thinking aloud RKT as follows:

$\{-\}$ [graphing] on the graph $\mathrm{v}$ against $\mathrm{t}$, here is $v_{0}=1$

Then vt his or $\mathrm{v}_{2}=2$ then there is $t_{0}=1_{\mathrm{t}_{0}}=1$ then $\mathrm{t}_{2}=2$ in this

graph is connected between $v_{t} \mathrm{v}_{0}$ and $\mathrm{v}_{\mathrm{t}} 2$ and $\mathrm{t}_{2}$, then $\mathrm{t}_{0}$ is not connected to the $\mathrm{v}_{0}$ and straight graph indicates no acceleration, then what is the meaning of acceleration equation of the graph. [write the formula] Equation velocity $v=s / t$ if $v=s / t$ means at a speed of 2 $\mathrm{m} / \mathrm{s}$ time of $2 \mathrm{~s}$, but the graphics are not depicted on the speed of 1 $\mathrm{m} / \mathrm{st}$ her $1 \mathrm{~s}$ so, then the equation is not quite right $\mathrm{v}=\mathrm{s} / \mathrm{t}$ due at time $\mathrm{t}$ it does not describe the acceleration, so we try equation $\mathrm{vt}=$ vo + at, $=1+\{?\}$ [understand the problem] $\{-\}$ [see chart] because this represents the area is not here right graph means at $\mathrm{V}_{0}=1, \mathrm{t}_{0}=1$,

$\mathrm{v}_{\mathrm{t}}=\mathrm{v}_{0}+$ at $v_{t}=v_{0}+\mathrm{at},=1+1.0$ Formula acceleration $\Delta \mathrm{v} / \mathrm{t}$

$=1 / 2.11=1$. That means really using the equation $\mathrm{v}_{\mathrm{t}}=\mathrm{v}_{0}+$ at.

RKT assume that the constant acceleration of the object at 1 $\mathrm{m} / \mathrm{s}-2$ so that changes in a regular speed. This was stated in an interview the following:

Interviewer:

Do you think the description of the results of the equation. How do you make it based on the chart?

RKT: that the speed chart with the equation that the acceleration initially his relationship $v$ t initially greater speed acceleration and initial velocity, the greater the speed

Interviewer: So this will be a constant acceleration?

RKT: $\quad Y e s$, based on the result of the constant

Interviewer: that?

RKT: $\quad 1 \mathrm{~ms}^{-2}$

\section{Representation and Transformation: Mathematical Equations - Graphs - Verbal}

Problem number three (Fig. 6), RKT was asked to represent the mathematical form to the shape of the graph and then perform the transformation verbally by describing the situation as represented by the equation. 


$$
s=v_{0} t+\frac{1}{2} a t^{2}
$$

Buat grafik yang mencerminkan persamaan di bawah ini Apa makna persamaan dari grafik yang Anda bua (deskripsikan)

Fig. 6. Equivalent Mathematical Context uniformly accelerated motion equation

RKT assumed that the problem is an equation of a uniformly accelerated motion. His written answer is presented in Fig. 7. He did not make the charts beforehand and immediately used way to prove this equation by working on every part of the equation. Here are the results of interviews conducted in respondents RKT.

Interviewer: I see you're using integral to prove the equation, it can be explained why this is so?

RKT:

because the first one I use integral, its intention to acquire this formula using the integral.

Interviewer: integral part what?

RKT: $\quad$ section $v_{0} t$

Interviewer: But do not be continued huh?

RKT: $\quad y e s$, no. I do not understand to continue, only proof of equality about it that I remember from the formula $v=\frac{s}{t}$ or $s=$ $v t$

In the transcript of thinking aloud RKT done similar things in the interview excerpts, the following transcript:

[read about] No. lastly, create graphics that reflect the equation below [write a formula] $s=v_{0} t+\frac{1}{2} e e^{2}$ is the formula essentially $s=v t$ because he lowered $e=d v$. $d t$ then $v$ we try to formula basically is $v t$ for $v=\frac{s}{t}$ this if $s=v t$ formula at time interval $t$ right $\int_{t_{0}}^{t_{1}} \quad v t$ derivatives since then means $v_{0} \mathrm{t}+$ $\frac{1}{2} e e^{2}$ which clearly using differential and integral at $v$, and $t$, but ... we reconsider $v_{0} \mathrm{t}+\frac{1}{2} e e^{2}$ formula basically $e=v t$ Then we try dv.dt. $\int_{t_{0}}^{t_{1}} \frac{1}{2} e e^{2} \mathrm{I}$ do not understand to further degrade so it gets $v_{0} t+\frac{1}{2} e e^{2}$ but essentially the formula $s=v t$

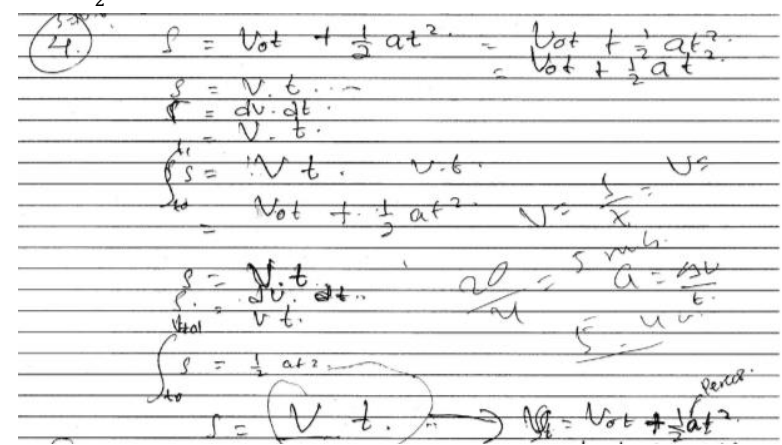

Fig. 7. The Answer Sheet of RKT

Fig. 7 shows respondents were able to transform the external representation. That is to say, the external representation can help resolve the problem. This statement is reinforced by [6] that the use of multiple representations when solving the problem may be advantageous, because the representational format may affect the achievement of the respondent and the use of representational learning strategies that can lead to substantial improvements in problem-solving.

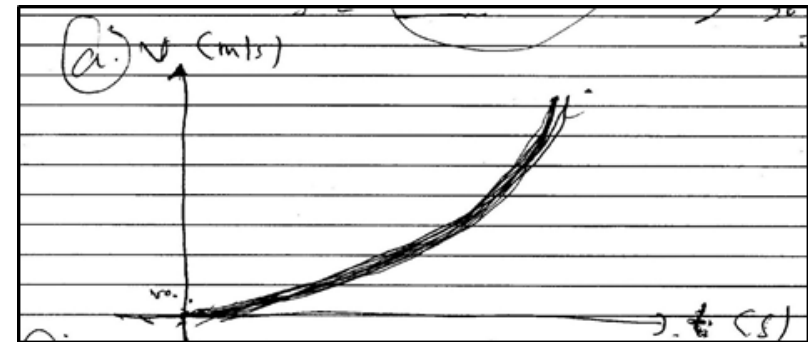

Fig. 8. Answer Sheet of RKT for No. 4 which representation to form graph

Fig. 8 shows RKT Respondents were able to do a representation to the shape of the graph. RKT graphs that reflect the similarities in the problem that displacement of the object is a quadratic function with respect to time. He described the parabolic graph opens upward to indicate that the positive displacement appreciating objects. The interview and transcript thinking aloud, respondents RKT understand graphs made. The following interview excerpt transcript of thinking aloud of RKT

$\begin{array}{ll}\text { Interviewer: } & \text { How graphics that you create can explain } \\ & \text { the similarities } v_{0} t+\frac{1}{2} e e^{2} \\ \text { RKT: } & \begin{array}{l}\text { because there is acceleration and time is a } \\ \text { quadratic function }\end{array}\end{array}$

[read about] [...] because here there is the result of a decrease in the formula is that is $s=v_{0} t+\frac{1}{2} e e^{2}$ because here there is $a$ here is the acceleration therefore and mark a positive means he accelerated accelerated because he was the exponent here means he describes the curve $\{-\}$ [drawing curves] means the curve like this because he's acceleration the curve is accelerated at a distance so then this is $v_{0}$ it then accelerated $t 2$.

Furthermore, for the representation and transformation into a verbal form, Fig. 9 shows respondents RKT can transform into a verbal form. Only, he can not physically interpret the equation. Respondents RKT simply transcribe a linear relationship between the acceleration and the speed of that of the equation.

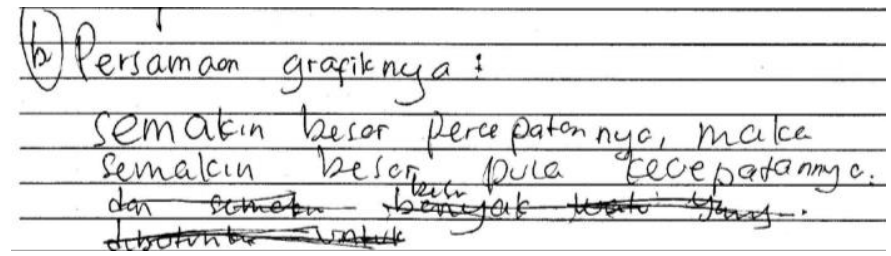

Fig. 9. Answer Sheet RKT to question No. 4 Transforms into verbal form.

\section{CONCLUSION AND RECOMMENDATION}

From this research, it can be stated that the respondent's ability to represent and transform the physical system is still fairly inadequate. In the context of the kinematics of rectilinear 
motion, the respondent was able to undertake the representation of the verbal representation to the representation of charts, graphs representation to a mathematical representation, and the mathematical representation to a graph representation. Neither in terms of transformation, the respondent was able to change the shape of the graph representation form to a mathematical representation, the mathematical representation to a verbal representation, and charts to a verbal. It was found that respondents use different problem-solving strategies, depending on the format of the representation presented [7]. Furthermore, the other findings showed that the higher categories of respondents were able to represent and transform original representation from a graphical representation to verbal, and low categories of respondents are better able to make a verbal representation and transformation into a mathematical equation. There is a dependency of the ability to transform to form the initial representation to the target representation and the context of external representation system.

A further research is needed to learning strategies in improving students' learning outcomes.

\section{ACKNOWLEDGMENTS}

We would like to thank Directorate of Higher, Ministry of National Education and Culture of Indonesia for funding this research in Hibah Tim Pascasarjana 2017 contract number: 696c/UN28.2/PL/2017. Secondly, we wish to thank I Komang Werdhiana for this validation and valuable discussion.

\section{REFERENCES}

[1] P. B. Kohl and N. D. Finkelstein, "Student representational competence and self-assessment when solving physics problems," Phys. Rev. Spec. Top. - Phys. Educ. Res., vol. 1, no. 1, pp. 1-11, 2005.

[2] E. Etkina et al., "Scientific abilities and their assessment," Phys. Rev. Spec. Top. - Phys. Educ. Res., vol. 2, no. 2, pp. 1-15, 2006.

[3] Leigh, "Experienced Secondary Science Teachers' Representation of Pedagogical Content Knowledge,” International J. Sci. Educ., vol. Vol 30 No., 2004.

[4] J. Mansyur, "Teachers' and Students' Preliminary Stages in Physics Problem Solving," Int. Educ. Stud., vol. 8, no. 9, pp. 1-14, 2015.

[5] \& V. H. Rosengrant, D., Etkina, E., "An Overview of Recent Research on Multiple Representations," State Univ. New Jersey, 2007.

[6] J. J. Solaz-portolés and V. S. Lopez, "Representations in problemsolving in science: Directions for practice," vol. 8 , no. 2 , pp. 1-17, 2007.

[7] M. De Cock, "Representation use and strategy choice in physics problem solving," Phys. Rev. Spec. Top. - Phys. Educ. Res., vol. 8, no. 2, pp. 1-15, 2012. 